Applied Research on Civil Engineering and Environment (ARCEE) VOL. 01 No. 01, August 2019

\title{
VULNERABILITY ASSESSMENT AT MT. BROMO INDONESIA BY USING TIME-SERIES LAND SURFACE DEFORMATION AND GIS
}

\author{
Arliandy P. Arbad ${ }^{1,2}$, W. Takeuchi², Y. Aoki ${ }^{3}$ Achmad Ardy ${ }^{4}$ \\ ${ }^{1}$ Dept. of Geomatics Engineering, Sumatera Institute of Technology, Lampung, 35365, Indonesia \\ ${ }^{2}$ Institute of Industrial Science, The University of Tokyo, Tokyo 153-8505, Japan \\ ${ }^{3}$ Earthquake Research Institute, The University of Tokyo, Tokyo 113-0032, Japan \\ ${ }^{4}$ dept. of grotechnology, Lampung University, Lampung, 35141, Indonesia \\ e-mail :arliandyarbad@gmail.com ${ }^{1,2}$
}

\begin{abstract}
About 127 active volcanoes are located in Indonesia. Mt. Bromo is one the most active volcano is located in Jawa Timur, type of Mt. Bromo is a strombolian. Many aspects that make volcano an interesting, we conduct a critical and comprehensive study and analysis concerning of volcano eruption based on remote sensing and GIS approaches. Nowadays, remote sensing play an important role to observe volcanic activity and facilitate real-time information. The method used in this study is the determination level of risk in the Mt. Bromo by Pairwise Comparison method. Vulnerability parameters to be obtained from the potential of land deformation, population density, and distance from the volcano dome. In addition, we used SAR data to observe time-series land surface deformation which obtained from ALOS-PALSAR datasets. The L-band frequency images are generated from ALOS Satellite (Advanced Land Observing and Sattelite). The PALSAR sensor type is an active microwave sensor to reach the limitations of the cloud which working on day nor night for monitoring land surface. We collected 22 PALSAR-images starts from May 24, 2007, until November 4, 2011. All the direction of datasets (track 91, frame 3780) is descending passes with Horizontal transmitting dan Horizontal receiving (HH) polarization. furthermore, the cities or municipalities with a specific level of a disaster have been classified and analyzed by using the Geographic Information System software. The main idea is providing hazard mitigation map at Mt. Bromo to provide adequate guidance for disaster-prone areas to create the policies of disaster risk management.
\end{abstract}

Keywords: Active Volcanoes; Deformation; Eruption; GIS; Vulnerability Assessment

\section{INTRODUCTION}

A large number of volcanoes are situated in the (so-called) ring of the fire area. Analysis from geographic and topographic data suggests that Indonesia is one of the countries with the most active volcano and a major eruption each year. Nevertheless, millions of people are living close to the volcanoes (Loughlin et al., 2015). About $13 \%$ of the world's active volcanoes are located in Indonesia. Tectonically, the active volcanoes are the result of a collision between Indian-Australian, Eurasian, and Philippine Plates (Zaennudin, 2010). Volcanic eruptions produce harmfull materials in a large size such as toxic gases, lava, volcanic tsunamis and pyroclastic fall (Tilling, 1989).

Scheme of Bromo volcano disaster event is a social catastrophe to the people who are living around the affected area. Due to the potential devastating of volcanic influence to urban settlements, we should prepared method and system based on understanding of volcanoes 
today. The fundamental study of volcano, related to dimensions, type of eruption, frequency of eruption, and the impact of the eruption. Even though volcanic eruptions produce harmful materials, those areas generally contain rich minerals which can be growth the prosperous harvest.

The objective of this study is to estimate disaster prone-areas based on time-series land deformation monitoring and volcanic materials, and number of population at Mt. Bromo.

\section{METHODS}

Synthetic Aperture Radar (SAR Images) The eruption of Bromo in 2010 will analyze by using SAR images from ALOS-PALSAR datasets. The L-band frequency images are generated from ALOS Satellite (Advanced Land Observing and Sattelite). The PALSAR sensor type is an active microwave sensor to reach the limitations of the cloud which working on day nor night for monitoring land surface. We collected 22 PALSAR-images starts from May 24, 2007, until November 4, 2011. All the direction of datasets (track 91, frame 3780) is descending passes with Horizontal transmitting dan Horizontal receiving $(\mathrm{HH})$ polarization.

Time-Series (TS-SAR Analysis)

For monitoring land deformation, we applied time-series analysis based on Small Baseline Interferometric (SBI) modules which TimeFun algorithm by Hetland et al.,(2011). The TimeFun method is an implementation of the temporal inversion scheme established formerly for multiscale interferometric time-series techniques directly in the data domain. This method allows to explain each pixel's phase evolution using a dictionary of user defined functions (Agram et al., 2013). By precisely selecting the interferometric image-pairs with short temporal baseline (Bt) and the perpendicular geometry to simplify the impact of image decorrelation is used the SBI-SAR analysis. Interferogram pairs are strictly limited by manually selecting the maximum baseline value after differential InSAR processing in single face working The observation equation for each pixel is:

$\Phi_{i j}=\sum \alpha_{k}\left(f^{k}\left(t_{i}\right)-f^{k}\left(t_{j}\right)\right)+e B_{p e r p}^{i j}$ $f^{k}(t): k$ th function

$\alpha_{k}:$ Coefficient associated with the kth function.

In this study, the Small Baseline Interferometric SAR (SBI-SAR) technique in three SBI-SAR approaches which applied in GIAnT softwarepackages which built in the StaMPS/MTI packages.

Vulnerability Assessment

Regarding the Ministerial Regulation No. 11 year 2016 of Ministry of Energy and Mineral Resources Indonesia (Kementerian ESDM) about the determination of Disaster-Prone Areas of Geological Hazard paragraph 1 point (2) and (6). Volcano hazard mitigation is an event how to reduce the risk of volcano hazard through the physical infrastructure nor establishing the awareness and ability for facing the volcano risk. Disaster-prone area of volcano hazard is the area which has inundated or identified as a potential hazard of a volcanic eruption with a direct nor indirect circumstances.

In this paper we used vulnerability assessment to create disaster proneareas. Vulnerability areas will be analyzed from each element at risk to assess their resistance to the impacts of different physical-effects. Vulnerability assessment in volcanic risk evalution (e.g. Aceves, Q., et al., 2007; and Dibben, C., et al., 1999) and the hazard 
event may influence the process of developing vulnerability for human assessment. Here, the risk level determined in the regional system is possibly appraised from the damage (Thierry, P., et al., 2008). The method of formulating the vulnerability assessment is Simple Additive Weight Method with the following equation:

$$
V=a(A)+b(B)+c(C)+d(D)+\ldots
$$

where,

$\mathrm{V}$

$$
=\text { Vulnerability Scale }
$$

$\mathrm{a}, \mathrm{b}, \mathrm{c}, \mathrm{d}=$ Value each Criterion

\section{$\mathrm{A}, \mathrm{B}, \mathrm{C}, \mathrm{D}=$ Criterion Assessment}

The criterions are used number of population, time-series land surface, distance from the summit of volcano, lava flow. Population density was selected as the main indicator for social vulnerability. The disaster measurement systems, zoning, and land-uses are needed to reduce the disaster risk, damage, and impact of hazardous from the volcanoes. Provide steps for problem solving clearly and concisely. It is recommended to explain with a flowchart, with no more than $15 \%$ words of the entire article.

\section{RESULTS AND DISCUSSION}

By using the GIS tool is enabled us to create several hazardous zoning related to the topographic and geological phenomena over Mt. Bromo from the three variables (land surface deformation, distance, and some population) corresponding to the major variable of disaster.

\section{Population Density}

Mt. Bromo is located at East Java Province which number total of population reach 38.85 million people. Our study focus on four cities (Kabupaten/Kota) surrounding Mt. Bromo, there are Pasuruan, Lumajang, Probolinggo and Malang. According to Indonesia national statistical agency, the number of population dramatically increase since 2010 to 2015 in cities which affected of Mt. Bromo activities as shown in figure 1 below.

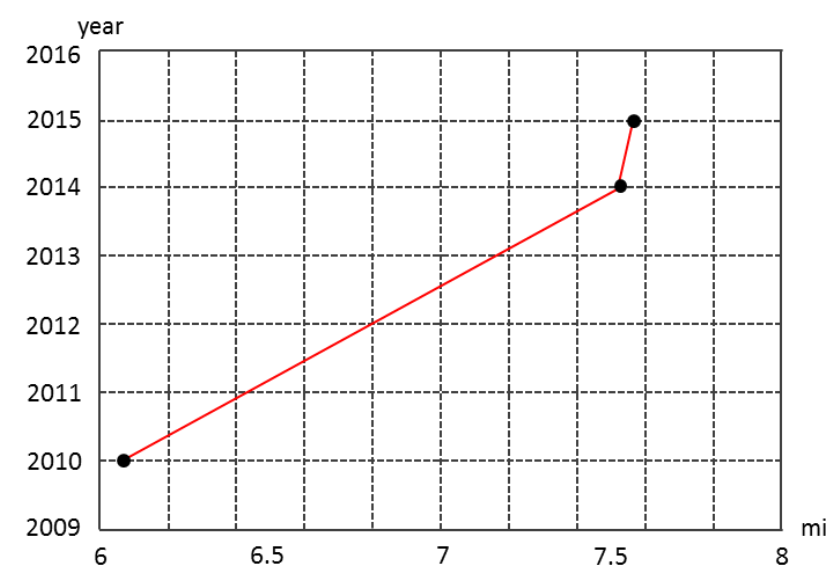

Figure 1. Number of Population in cities affected of Mt. Bromo hazard from 2010 to 2015 based on national census. (data source taken from Indonesia National Statistical Agency, 2016). (mi) mean Million.

\section{Hazard Zoning}

We divided into three hazard zoning areas, high intensity, medium intensity and low intensity. We defined the intensity as the physical impact on the exposed elements and environments.
The potential intensity should be described on a the consistent-scale among all the phenomena. We divided into three categories of hazard intensity, where: 
a. The high hazard intensity will be named Disaster-Prone areas III,

b. The medium hazard intensity will be named Disaster-Prone areas II, and

c. The lower hazard intensity will be named Disaster-Prone areas I.

The first step is to establish a matrix pairwise of each criterion of the element of vulnerability (matrix pairwise comparison) to determine the level of interest among group criteria elements by providing an assessment based on assessment index that had been developed by Saaty (1990) as shown in Table 1. This method involves pairwise comparisons to create a matrix ratio in decision making (Malczewski, 1999).

Table 1. Matrix Pairwise of vulnerability elements

\begin{tabular}{lcccc}
\hline \multicolumn{1}{c}{ Matrix Pairwise } & Population & Land Deformation & $\begin{array}{c}\text { Distance From } \\
\text { Lava }\end{array}$ & $\begin{array}{c}\text { Criterion } \\
\text { Weight }\end{array}$ \\
\hline $\begin{array}{l}\text { Population } \\
\text { Land Deformation }\end{array}$ & 1.0 & 0.333 & 0.25 & 0.124 \\
Disatance From Lava & 3.0 & 1.0 & 0.667 & 0.358 \\
\hline
\end{tabular}

The greater value of criterion weight, that mean more important to consider as hazard. The formula of the level of vulnerability of each component were calculated using a simple additive weight formula as shown table 2 below.

Table 2. Simple additive weight calculation

\begin{tabular}{lccc}
\hline \multicolumn{1}{c}{ Disaster Prone Areas } & I & II & III \\
\hline Population & Low & Medium & High \\
Land Deformation & Small & Medium & Large \\
Distance From Lava & $30 \mathrm{Km}$ & $20 \mathrm{Km}$ & $10 \mathrm{Km}$ \\
\hline
\end{tabular}




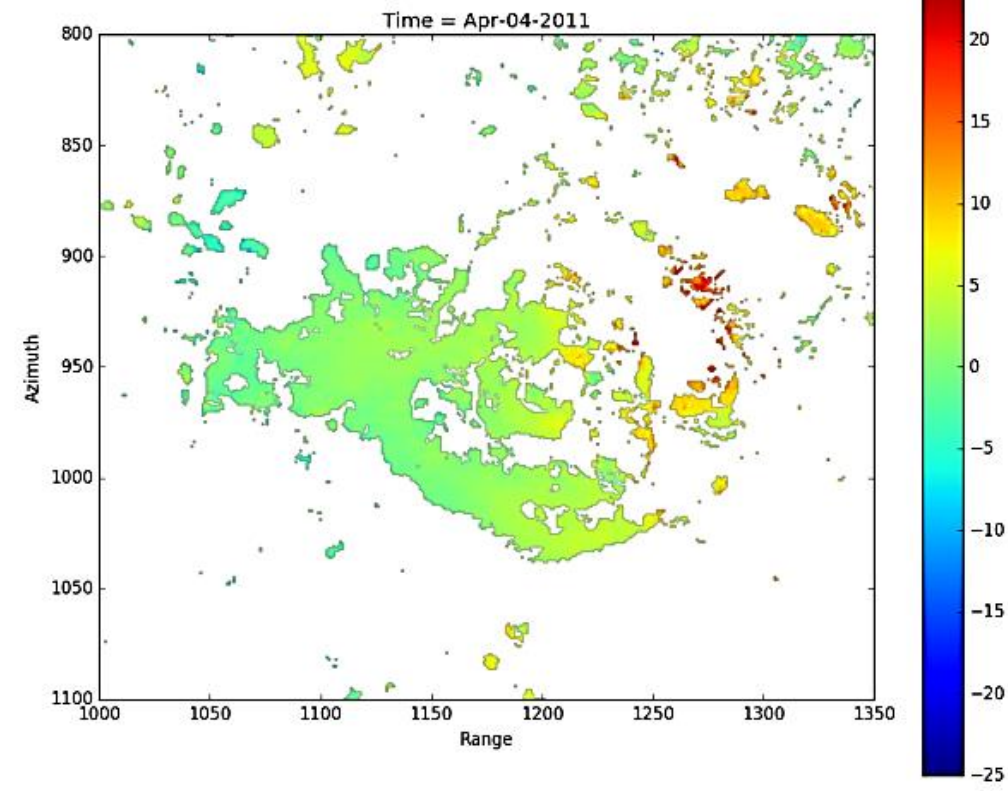

Figure 2. Time-series displacement results of Mt. Bromo for period 2007-2011 with the color range unit of centimeters based on TimeFun algorithm.

At the Mt. Bromo most of pixels were processed with 110 interferoframs, with a fully selected temporal and spatial network, the particularly coherent pixels that caused of sandy area at Mt. Bromo. We overlayed the result of time series map with another elements in simple additive method. We calculated the criterion weight -5 to 5 is lower intensity, -10 to 10 is medium more than 10 is high intensity.

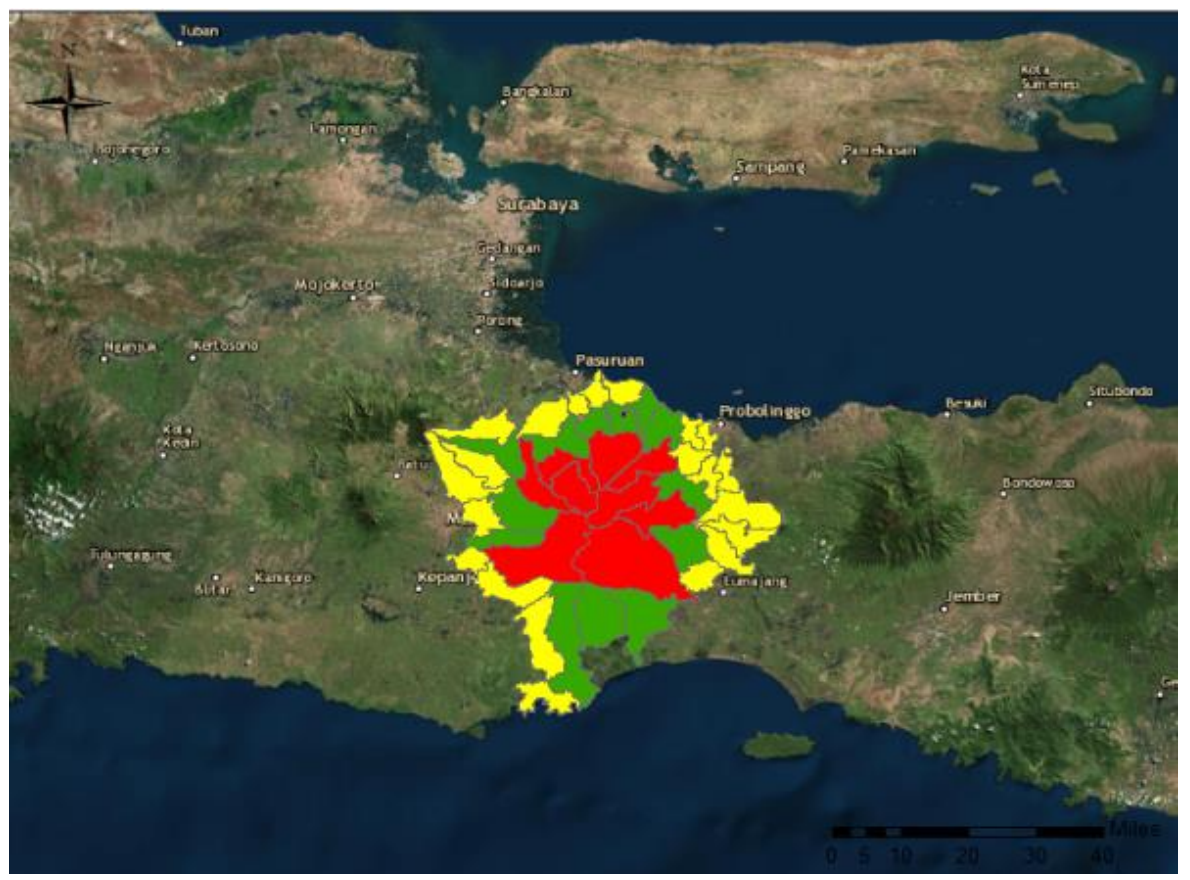

Figure 3. Disaster-prone areas caused of Mt. activities in East Java province. The Red color as representative of high intensity, the green color as representative of medium intensity and the yellow color as representative of lower intensity. 
To generate the classification of the cities with very high vulnerability, the disaster-prone areas are modeled by adding the weights of the three variables (Population, land deformation and distance from the source). A reconstruction of the lava and other volcanic hazard materials at Bromo volcano by comparing the eruptive history and Lahar-Z applications, report based on our field study, information derived from the local residents and visiting post-observation of Mt. Bromo in Ngadisari village, Sukapura District, Probolinggo.

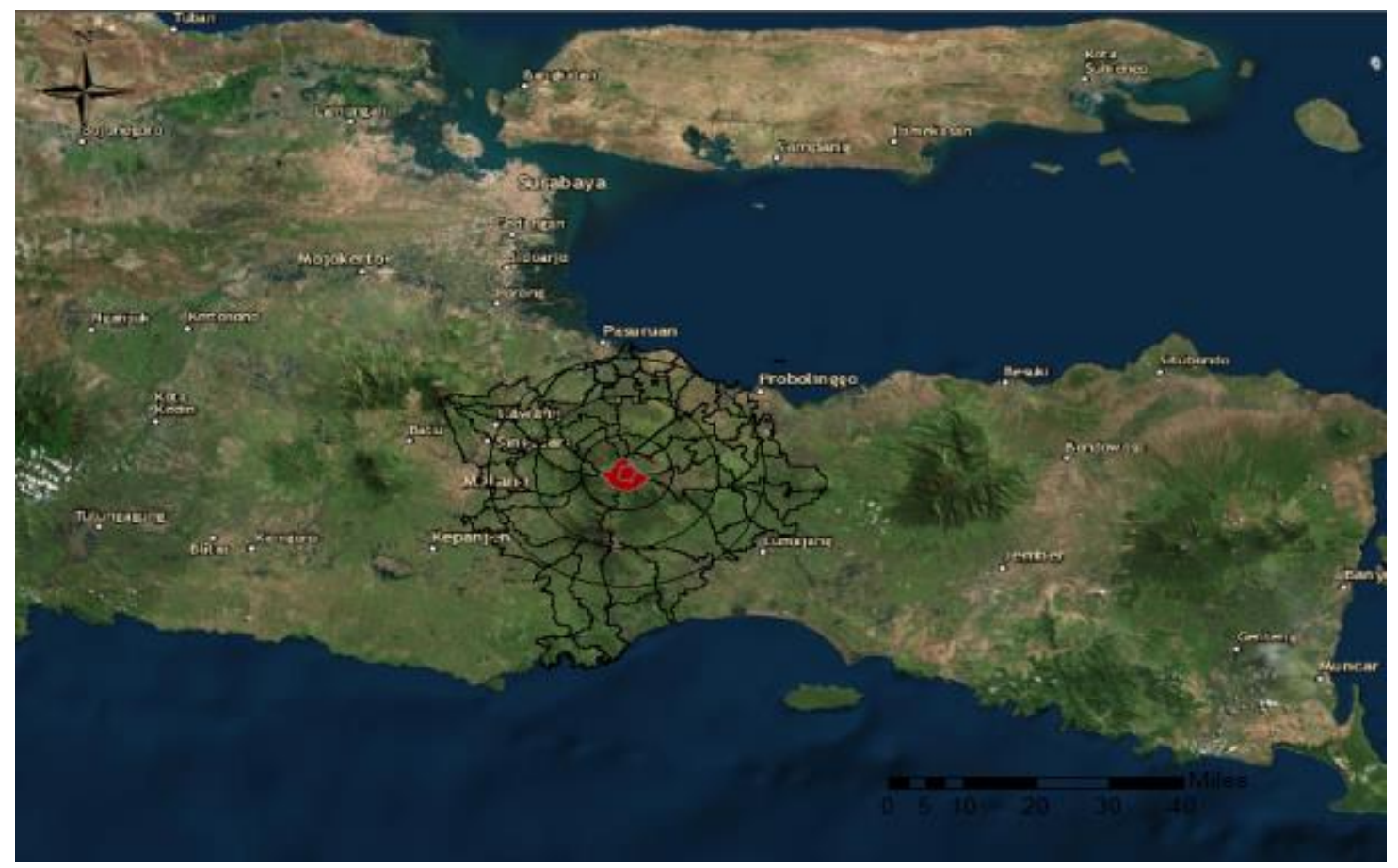

Figure 4. The estimation area which affected by lava flow based on interpretation of Mt. Bromo in the past eruption and simulation by using Lahar-Z application.

Existing methods either use data with limited suitability and availability (census data). By this study, We deals with the assessment of social vulnerability involves the time series land surface changes which can be evoke the landside. Risk assessment to support management requires knowledge about present nor future hazards, elements at disaster-risk and different types of vulnerability level. Moreover, we can add another secondary datasets such as precipitation, and also housing assessment index.

\section{CONCLUSION}

By this study, we found three sub-cities with larger percentage of risk area based on the analytical hierarchy process model are Sukapura, Sumber and Tosari. The most important principle of practise of the GIS implementation is constituted a distinctive information integration and management system that allows interpretation of spatial and characteristic information in effective process, rapid and integrated way. Moreover, it creates a great practice of the intense capacity of spatial technology in few information layers, data extraction in a relevant, and a real-time updating for the information at a single project for providing the decision. 


\section{ACKNOWLEDGEMENT}

Many thanks to Wataru Takeuchi Lab's Dept. of Civil Engineering U-tokyo and Earthquake Research Institute for transferring knowledge on the volcano sight.

\section{REFERENCES}

Aceves-Quesada, J. F., Díaz-Salgado, J., \& López-Blanco, J. (2007). Vulnerability assessment in a volcanic risk evaluation in Central Mexico through a multi-criteriaGIS approach. Natural Hazards, 40(2), 339-356.

Agram, P. S., Jolivet, R., Riel, B., Lin, Y. N., Simons, M., Hetland, E., Doin, M. P., \& Lasserre, C. (2013). New radar interferometric time series analysis toolbox released. Eos, Transactions American Geophysical Union, 94(7), 69-70.

Dibben, C., \& Chester, D. K. (1999). Human vulnerability in volcanic environments: the case of Furnas, Sao Miguel, Azores. Journal of Volcanology and Geothermal Research, 92(1-2), 133-150.

Hetland, E. A., Musé, P., Simons, M., Lin, Y. N., Agram, P. S., \& DiCaprio, C. J. (2012). Multiscale InSAR time series (MInTS) analysis of surface deformation. Journal of Geophysical Research: Solid Earth, 117(B2).

Loughlin, S. C., Sparks, R. S. J., Sparks, S., Brown, S. K., Jenkins, S. F., \& Vye-Brown, C. (Eds.). (2015). Global volcanic hazards and risk. Cambridge University Press. Malczewski, J. (1999). GIS and multicriteria decision analysis. John Wiley \& Sons.

Peraturan Menteri ESDM No. 11 Tahun 2016 Tentang Penetapan Kawasan Rawan Bencana Geologi.
Saaty, T. L. (1990). How to make a decision: the analytic hierarchy process. European journal of operational research, 48(1), 9-26.

Saaty, T. L. (2008). Decision making with the analytic hierarchy process. International journal of services sciences, 1(1), 83-98.

The activity of Mt. Bromo Indonesia reported by CVGHM Indonesia, Bromo Post Observation. http://www.vsi.esdm.go.id/index. php/gunungapi/aktivitasgunungapi/1096-evaluasi-tingkataktivitas-g-bromo-hingga-tanggal22-januari-2016-pukul-0600-wib

Thierry, P., Stieltjes, L., Kouokam, E., Nguéya, P., \& Salley, P. M. (2008). Multi-hazard risk mapping and assessment on an active volcano: the GRINP project at Mount Cameroon. Natural Hazards, 45(3), 429-456.

Tilling, R. I. (1989). Volcanic hazards and their mitigation: progress and problems. Reviews Geophysics, 27(2), 237-269.

Zaennudin, A. (2010). The characteristic of eruption of Indonesian active volcanoes in the last four decades. Jurnal Lingkungan dan Bencana Geologi, 1(2), 113-129. 